\title{
Effects of Statin Therapy on Endothelial Function in Asymptomatic Metabolic Syndrome
}

\author{
Boochi Babu Mannuva ${ }^{1}$, Rajasekhar Durgaprasad ${ }^{1}$, Vanajakshamma Velam¹, \\ Vinod Kumar Mustyala ${ }^{1}$, Latheef Kasala ${ }^{1}$, Ashok Thakkar ${ }^{2}$ \\ ${ }^{1}$ Department of Cardiology, Sri Venkateswara Institute of Medical Sciences (SVIMS), Tirupati, India; ${ }^{2}$ Department of Clinical Trials, \\ Sahjanand Medical Technologies Pvt Ltd, Surat, India. \\ Email: drdrsekhar@yahoo.co.in
}

Received January $8^{\text {th }}$, 2014; revised January 31 ${ }^{\text {st }}$, 2014; accepted February $15^{\text {th }}, 2014$

Copyright (C) 2014 Boochi Babu Mannuva et al. This is an open access article distributed under the Creative Commons Attribution License, which permits unrestricted use, distribution, and reproduction in any medium, provided the original work is properly cited. In accordance of the Creative Commons Attribution License all Copyrights (C) 2014 are reserved for SCIRP and the owner of the intellectual property Boochi Babu Mannuva et al. All Copyright (c) 2014 are guarded by law and by SCIRP as a guardian.

\section{ABSTRACT}

Context: Endothelial dysfunction is an early predictor of adverse cardiovascular events. The present study evaluated asymptomatic metabolic syndrome (MS) patients with brachial artery endothelial dysfunction to determine whether a reversal of endothelial dysfunction occurs with statin treatment. Aim: To evaluate the short term effects of statins on endothelial function in asymptomatic metabolic syndrome patients. Methodology: This was a prospective, single centre, case-control study. We evaluated 50 recently diagnosed newly detected asymptomatic MS patients who underwent an assessment of endothelial function by brachial artery flow-mediated dilation (FMD) before and after treatment with $\mathbf{4 0}$ mg atorvastatin for one week. Results: A total of 50 MS patients, including $36(62 \%)$ females and $14(38 \%)$ males, were included in the study. The mean age of the patients was $49.70 \pm 8.84 \mathrm{y}$. We identified a significant difference between cases and age- and sex-matched controls regarding baseline brachial artery FMD\% $(6.73 \pm 2.55$ vs. $11.03 \pm 1.85$, respectively; $p<0.001)$. Significant negative correlations were detected between FMD \% and HDL-cholesterol $(r=-0.34, p=0.01)$, fasting blood sugar $(r=-0.40, p$ $=0.004)$, and systolic blood pressure $(r=-0.34, p=0.015)$. Multiple linear regression analysis indicated that HDL-cholesterol was an independently associated factor for FMD. MS patients treated with $\mathbf{4 0} \mathbf{~ m g}$ atorvastatin for one week showed a significant improvement in brachial artery FMD \% $(6.73 \pm 2.55$ before treatment vs. $10.19 \pm 3.01$ after treatment, $p<\mathbf{0 . 0 0 1}$ ). Conclusions: MS is associated with endothelial dysfunction and decreased brachial artery FMD compared with controls. Statin treatment for one week significantly improved brachial artery endothelial function in MS patients.

\section{KEYWORDS}

Metabolic Syndrome; Endothelial Dysfunction; Flow-Mediated Dilation; Brachial Artery; Statin

\section{Introduction}

Metabolic syndrome (MS) is characterized by insulin resistance and a clustering of cardiovascular risk factors that includes the following: hypertension; obesity; hypertriglyceridemia; the presence of small, dense low-density lipoprotein particles (LDL); a low level of high-density lipoprotein cholesterol (HDLC); and hypercoagulability [1]. Several definitions have been proposed for the diagnosis of MS. The most commonly used are those by the World Health Organization (WHO), the International
Diabetes Federation (IDF), and the National Cholesterol Education Program (NCEP)_-Adult Treatment Pannel III (ATP-III). In our study, we applied the revised NCEP ATP III criteria [2]. According to these criteria, a diagnosis of MS requires at least three of the followings: blood pressure $\geq 130 / 85$ or undergoing antihypertensive treatment, triglyceride levels $\geq 150 \mathrm{mg} / \mathrm{dL}$ or treatment for elevated triglycerides, HDLC levels $<40 \mathrm{mg} / \mathrm{dL}$ (for men) or $<50 \mathrm{mg} / \mathrm{dL}$ (for women) or treatment for low HDL-C, waist circumference $>102 \mathrm{~cm}$ (for men) or $>88$ $\mathrm{cm}$ (for women), and fasting glucose levels $\geq 100 \mathrm{mg} / \mathrm{dL}$ 
or treatment for elevated blood sugar.

Individuals with MS are at a three-fold greater risk of coronary heart disease and stroke and more than a fivefold greater risk of cardiovascular mortality [3]. Endothelial dysfunction, characterized by decreased nitric oxide (NO) bioavailability, is a key early event in atherogenesis that occurs long before structural atherosclerotic changes and promotes cardiovascular events [4-6]. NO is released from endothelial cells in response to increased shear stress and certain pharmacologic stimuli [7]. NO may function as an endogenous antiatherogenic molecule by maintaining low arterial tone at rest, inhibiting leucocyte-endothelial interactions, attenuating platelet aggregation and inhibiting smooth muscle cell proliferation. [7]

Previous studies have reported that obesity, low HDLC, impaired glucose tolerance, hypertension, and hypertriglyceridemia all are associated with endothelial dysfunction [8-11]. Most of these studies tested endothelial function in the context of individual components of MS; data regarding endothelial function across the full spectrum of asymptomatic MS are scarce. The present study considered all five components of MS, i.e. impaired fasting glucose, hypertension, hypertriglyceridemia, low HDL$\mathrm{C}$, and obesity.

Endothelial function can be assessed invasively or non-invasively. Previous studies have shown that endothelial function assessed using intra-arterial infusion of the endothelium-dependent vasodilator, acetylcholine, in a coronary or peripheral artery identifies individuals at increased risk for cardiovascular disease (CVD) events [12-15]. Because of its invasive nature, this technique has been applied only to small studies, and large epidemiological studies are lacking. The assessment of endothelial function by flow-mediated dilation (FMD) of the brachial artery has been proposed as a non-invasive surrogate marker for cardiovascular risk [16-18].

Several large clinical trials have demonstrated that statins markedly decrease the incidence of cardiovascular events in hypercholesterolemic individuals [19-21]. However, some studies have reported that the restoration of endothelial function precedes a significant reduction in serum cholesterol levels, suggesting additional effects of statins on endothelial function beyond that of cholesterol reduction [19-22]. Previous studies investigating the short-term effects of statin treatment on endothelial dysfunction in various patient groups have indicated that statins could improve endothelial function significantly as early as $3 \mathrm{~h}$ after treatment and even with a single dose [23-27].

The present study evaluated MS patients with brachial artery endothelial dysfunction to determine whether a reversal of endothelial dysfunction occurs with statin treatment.

\section{Methodology}

\subsection{Study Design}

Fifty MS patients who attended the Hypertension Clinic conducted by the Department of Cardiology, Sri Venkateswara Institute of Medical Sciences Hospital, Tirupati, Andhra Pradesh, India. Fifty age- and sex-matched healthy controls were included in this study. Informed consent was obtained from each subject in accordance with the ethical guidelines of the 1975 Declaration of Helsinki. This study was approved by the Institutional Ethics committee of Sri Venkateswara Institute of Medical Sciences (SVIMS), Tirupati, Andhra Pradesh, India.

\subsection{Study Population}

Inclusion criteria for the present study were as follows: confirmed MS as per the ATP III criteria. [2]

Exclusion criteria: Subjects were excluded from the study for any of the following: younger than $30 \mathrm{y}$ or older than $65 \mathrm{y}$, history of smoking, already on statin treatment, secondary hypertension, ischemic heart disease, peripheral arterial diseases, Cardiomyopathy, valvular heart diseases, or rhythm disorders.

\subsection{Study Methods}

Detailed clinical histories were collected from all subjects that included age, sex, and duration of hypertension, ischemic heart disease, diabetes mellitus (DM), and smoking. All patients underwent complete clinical examinations of their pulse, blood pressure, and respiratory, cardiovascular, and central nervous systems. A dedicated physician was responsible for all blood pressure, weight, and waist circumference measurements and performed measurements under strict instructions without any knowledge of the study protocol or objectives. Waist circumference was measured using non-stretchable flexible tape at a horizontal position just above the iliac crest. Measurements were made at the end of normal expiration, in the fasting state, and with the subject standing erect and looking straight forward with the observer sitting in front of the subject. Hypertension was diagnosed according to Joint National Committee 7 criteria [28]. Serum total cholesterol, triglycerides, and HDL-C concentrations were quantified by using commercially available kits on auto-analyzer (Synchron CX9 from Beckman, USA). LDL cholesterol was calculated using Friedewald's formula [29]. Fasting blood sugar (FBS) was measured using the glucose oxidation-peroxidation method. Dyslipidemia was considered per NCEP ATP-III guidelines [1]. DM was defined using the American Diabetes Association 2007 criteria [30]. Resting 12-lead electrocardiograms were performed on every patient. All patients were given $40 \mathrm{mg}$ atorvastatin for one week as 
part of the study immediately after recruitment.

\section{Flow mediated dilatation:}

Endothelial function was assessed by measuring the diameter of the brachial artery in MS cases and healthy controls using a vascular Doppler probe of 7.5 to 10 $\mathrm{MHz}$ (iE33 2D Ultrasound machine, Philips Sonos, Netherlands), as described previously. [4] Briefly, after resting for ten minutes (base-line diameter), the right forearm was compressed by inflation of a pneumatic tourniquet at a pressure of $300 \mathrm{~mm} \mathrm{Hg}$ for five minutes. The diameter of the brachial artery was measured $60 \mathrm{~s}$ after the release of pressure. The diameter of the brachial artery was measured again 15 min after deflation of the cuff to ensure that baseline had been reached. After using a statin for one week, the diameter of the brachial artery was measured at baseline and $60 \mathrm{~s}$ after the release of pressure.

\section{Calculation of FMD:}

FMD was calculated using the equation: FMD $=(\mathrm{d} 2-$ d1) $\times 100 / d 1$; where $\mathrm{d} 1$ is the brachialartery diameter at baseline, and $\mathrm{d} 2$ is the brachial artery diameter $60 \mathrm{~s}$ after cuff release. FMD was expressed as a per cent change (FMD\%). The coefficient of variation of FMD measurement in our study was $1.2 \% \pm 0.2 \%$ intra-assay and $3.5 \%$ $\pm 1.0 \%$ inter-assay.

\subsection{Statistical Analysis}

Data were analysed using SPSS 16.0 for Windows (SPSS Inc. Chicago, USA). Continuous variables were represented as mean \pm standard deviation (SD). Differences in continuous variables between cases and controls were analysed by unpaired student's t-test. Pearson's correlation coefficients (two-sided) were derived to assess the relationships between continuous variables and FMD\%. One-way analysis of variance (ANOVA) was used to assess the relationship between the mean values for FMD\% and the number of NCEP ATP III metabolic diagnostic criteria identified in each subject. Stepwise multivariate logistic regression models were produced to investigate independent determinants of FMD\% in the brachial artery using HDL-C levels, systolic blood pressure (SBP), and FBS as co-variants. A $p$-value $<0.05$ was considered statistically significant.

\section{Results}

\subsection{Baseline Characteristics}

The mean ages of the cases and controls were $49.70 \pm$ 8.84 years and $48.60 \pm 7.73$ years, respectively (Table 1 ). Sixty-two percent of cases and 58\% of controls were females. The mean SBP and diastolic blood pressure (DBP) in MS patients were $137.40 \pm 9.00$ and $82.40 \pm$ 9.50 , respectively. The mean values of MS components were as follows: FBS, $123.56 \pm 42.00 \mathrm{mg} \%$; waist cir-
Table 1. Baseline characteristics of cases and controls.

\begin{tabular}{cccc}
\hline Variable & Cases & Controls & $\boldsymbol{p}$-Value \\
\hline Age (yrs) & $49.70 \pm 8.84$ & $48.06 \pm 7.73$ & 0.32 \\
Male/Female & $19 / 31$ & $21 / 29$ & $\mathrm{NS}^{2}$ \\
$\mathrm{SBP}^{3}(\mathrm{mmHg})$ & $137.40 \pm 19.00$ & $122.00 \pm 12.00$ & $0.0001^{*}$ \\
$\mathrm{DBP}^{4}(\mathrm{mmHg})$ & $82.40 \pm 9.50$ & $78.24 \pm 6.41$ & $0.0118^{*}$ \\
$\mathrm{FBS}^{5}(\mathrm{mgs} \%)$ & $123.56 \pm 42.62$ & $92.40 \pm 14.67$ & $0.0001^{*}$ \\
$\mathrm{WC}^{6}(\mathrm{cms})$ & $100.70 \pm 6.98$ & $94.40 \pm 6.80$ & $0.0001^{*}$ \\
$\mathrm{TG}^{7}(\mathrm{mgs} \%)$ & $199.82 \pm 99.81$ & $156.63 \pm 14.43$ & $0.0031^{*}$ \\
$\mathrm{HDL}^{*}{ }^{8}(\mathrm{mgs} \%)$ & $39.60 \pm 8.31$ & $45.20 \pm 7.03$ & $0.0004^{*}$ \\
$\mathrm{FMD}^{9} \%$ & $6.73 \pm 2.55$ & $13.50 \pm 3.30$ & $0.0001^{*}$ \\
\hline
\end{tabular}

cumference, $100.70 \pm 6.98 \mathrm{~cm}$; serum triglycerides, $199.80 \pm 99.00$ mgs\%; serum HDL-C, $39.60 \pm 8.00$ mgs\%. Twenty-five (50\%) patients had 3 metabolic components associated with MS, 18 (36\%) patients had four components, and seven (14\%) patients had all five components.

\subsection{Association between FMD and MS}

The mean FMD\% values in cases and controls before statin treatment were $6.73 \% \pm 2.55 \%$ and $11.03 \% \pm$ $1.85 \%$, respectively. A significant difference between baseline brachial artery FMD\% in cases and controls was detected $(p<0.001)$. Pearson's correlation analysis between FMD\% and other variables is shown in Table 2. Significant negative correlations were found between FMD and HDL-C ( $\mathrm{r}=-0.34, p=0.01)$, FMD and FBS ( $\mathrm{r}$ $=-0.040, p=0.004)$, and FMD and SBP $(r=-0.034, p=$ $0.015)$. No significant correlations were identified between FMD and age, waist circumference, DBP, triglycerides, or number of components of MS.

\subsection{Multiple Linear Regression Analysis}

Multiple linear regression analysis indicated that only HDL-C was an independently associated factor for FMD (Table 3).

\subsection{FMD \% before and after Statin Therapy}

The mean FMD\% values in cases before and after statin treatment were $6.73 \% \pm 2.55 \%$ and $10.19 \% \pm 3.01 \%$, respectively. The change in FMD\% after statin treatment

\footnotetext{
${ }^{1} p<0.05$ indicates statistically significant difference.

${ }^{2}$ not significant.

${ }^{3}$ Systolic blood pressure.

${ }^{4}$ Diastolic blood pressure.

${ }^{5}$ Fasting Blood sugar.

${ }^{6}$ Waist circumference.

${ }^{7}$ Triglycerides.

${ }^{8}$ High-density lipoprotein cholesterol.

${ }^{9}$ Flow-mediated dilation.

${ }^{*} p<0.05$, statistically significant difference.
} 
Table 2. Correlation of flow mediated dilation \% and other variables.

\begin{tabular}{ccc}
\hline Variable & Mean \pm SD & $\begin{array}{c}\text { Correlation } \\
\text { Coefficient (r) with } \\
\text { FMD \% }\end{array}$ \\
\hline Age & $49.78 \pm 8.84$ & $-0.17(p=0.24)$ \\
FBS (mgs\%) & $123.42 \pm 42.11$ & $-0.40\left(p=0.004^{*}\right)$ \\
SBP (mmHg) & $137.48 \pm 19.32$ & $-0.34\left(p=0.015^{*}\right)$ \\
DBP (mmHg) & $82.40 \pm 9.50$ & $-0.10(p=0.49)$ \\
TG (mg\%) & $199.88 \pm 99.80$ & $0.04(p=0.73)$ \\
HDL-C (mg\%) & $39.68 \pm 8.11$ & $-0.34\left(p=0.01^{*}\right)$ \\
WC (cms) & $100.70 \pm 6.98$ & $0.11(p=0.47)$ \\
$\begin{array}{c}\text { Number of components } \\
\text { of metabolic syndrome }\end{array}$ & Not applicable & $-0.20(p=0.15)$ \\
\hline
\end{tabular}

Table 3. Coefficients of multiple regression analysis.

\begin{tabular}{ccccccc}
\hline \multirow{2}{*}{$\begin{array}{c}\text { Independent } \\
\text { Variables }\end{array}$} & \multicolumn{2}{c}{$\begin{array}{c}\text { Unstandardized } \\
\text { Coefficients }\end{array}$} & $\begin{array}{c}\text { Standardized } \\
\text { Coefficients }\end{array}$ & \multirow{2}{*}{$\mathrm{t}$} & $p$ \\
\cline { 2 - 4 } & $\mathrm{B}$ & Std. Error & Beta & & \\
\hline Constant & 12.495 & 2.868 & & 4.343 & 0.000 \\
HDL-C $^{10}$ & -0.104 & 0.045 & -0.327 & -2.333 & $0.024^{*}$ \\
$\mathrm{SBP}^{11}$ & -0.009 & 0.022 & -0.067 & -0.405 & 0.687 \\
FBS $^{12}$ & -0.003 & 0.010 & -0.050 & -0.304 & 0.763 \\
\hline
\end{tabular}

Dependent variable: Flow-mediated dilatation.

was $3.46 \%$. MS patients treated with $40 \mathrm{mg}$ atorvastatin for one week showed a significant improvement in brachial artery FMD\% $(p<0.001)$ (Figure 1).

\subsection{FMD\% Change in Subjects with Hypertension and Diabetes Mellitus}

No significant difference was detected between baseline FMD values in MS subjects with $(6.55 \% \pm 2.70 \%)$ or without hypertension $(7.19 \% \pm 2.13 \%, p=0.435$, Table 4). Statin treatment significantly improved brachial artery FMD in patients without hypertension $(11.52 \% \pm 2.61 \%)$ compared with patients with hypertension $(9.68 \% \pm$ $3.03 \%, p=0.04$ ). Before statin treatment, brachial artery FMD values did not differ significantly in subjects with $(6.23 \% \pm 2.61 \%)$ or without DM $(7.62 \% \pm 2.23 \%, p=$ 0.065 , Table 4). After statin treatment, significant improvements in brachial artery FMD were detected in diabetics and non-diabetics; this improvement was more pronounced in non-diabetic subjects $(p=0.02)$. Among patients with both hypertension and DM, statin treatment improved the FMD\% from a baseline of $5.7 \% \pm 2.76 \%$ to $8.49 \% \pm 2.55 \%(p=0.001$, Table 4$)$. After statin treatment, a significant improvement in brachial artery FMD\%

\footnotetext{
${ }^{10}$ High-density lipoprotein cholesterol.

${ }^{11}$ Systolic blood pressure.

${ }^{12}$ Fasting Blood sugar.
}

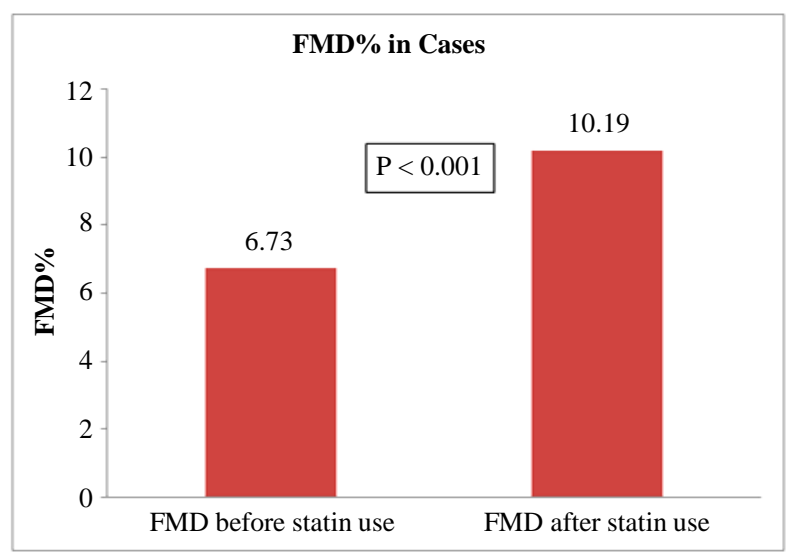

Figure 1. Flow-mediateddilation (FMD) before and after statin use.

was detected in patients with both hypertension and DM (8.49 \pm 2.55$)$ compared to patients without hypertension or $\mathrm{DM}(12.20 \pm 3.31, p=0.03)$.

\section{Discussion}

MS has received increased attention during the past few years because it is associated with an increased risk of type 2 DM, CVD and premature mortality [3,31,32]. The mode by which MS increases the risk of CVD is not completely understood.

A large body of evidence has suggested that the presence of endothelial dysfunction represents a major promoter for atherosclerosis and thrombosis and is an independent prognostic predictor for the risk of future cardiovascular events in several groups of patients [33,34]. Endothelial dysfunction, as detected by FMD measurements in the brachial artery, has been shown to be an independent predictor of cardiovascular outcomes [17,35-39]. It is well known that the five components of MS can individually impair endothelial function. Previous studies have shown that obesity, low HDL-C, impaired glucose tolerance, hypertension, and hypertriglyceridemia are associated with decreased endothelium-dependent vasodilation [8,9]. Furthermore, treatments targeted at these conditions improve endothelial function [40,41].

Examining the input of each MS component in the pathogenesis of endothelial dysfunction in MS patients, Lind et al. reported that triglyceride levels, waist circumference, and DBP independently predicted endothelium-dependent vasodilation [42]. Endothelial dysfunction was more strongly related to waist circumference followed by triglyceride levels and DBP [42]. Lteif et al. reported that insulin resistance, SBP, and ethnicity are the principal determinants of endothelial dysfunction in MS [43]. In another study, only HDL-C levels were independently associated with reduced FMD in patients with MS [44]. Hamburg et al. [45] and Melikian et al. 
Table 4. Mean flow mediated dilation\% change in hypertension and diabetes mellitus subjects.

\begin{tabular}{|c|c|c|c|c|c|c|c|c|c|}
\hline & With HTN & Without HTN & $p$-val & With DM & Without DM & $p$-val & Both HTN \& DM & Without HTN \& DM & $p$-val \\
\hline $\begin{array}{c}\text { FMD \% before } \\
\text { statin }\end{array}$ & $6.55 \pm 2.70$ & $7.19 \pm 2.13$ & 0.435 & $6.23 \pm 2.62$ & $7.62 \pm 2.23$ & 0.065 & $5.70 \pm 2.76$ & $6.93 \pm 2.93$ & 0.48 \\
\hline $\begin{array}{c}\text { FMD\% after } \\
\text { statin }\end{array}$ & $9.68 \pm 3.03$ & $11.52 \pm 2.61$ & $0.04^{*}$ & $9.47 \pm 2.86$ & $11.49 \pm 2.9$ & $0.02^{*}$ & $8.49 \pm 2.55$ & $12.20 \pm 3.31$ & $0.03^{*}$ \\
\hline$p$-val & $<0.001^{*}$ & $<0.001^{*}$ & & $<0.001^{*}$ & $<0.001^{*}$ & & $<0.001^{*}$ & $<0.001^{*}$ & \\
\hline
\end{tabular}

*Indicates significant $p$-value, i.e. $p<0.05$.

[46] observed progressively decreasing vasodilator function with an increasing number of MS components.

In our study, FMD was significantly decreased in patients with MS when compared with healthy controls. Low FMD values are due to the effect of several risk factors of atherosclerotic disease on NO bioavailability. Our study indicated that among the five components of MS, serum HDL-C, FBS, and SBP were significantly negatively correlated with brachial artery FMD\%. However, regression analysis showed that only HDL-C was independently associated with endothelial dysfunction in MS. This can be attributed to the endothelial protective effects of HDL-C. Prior studies demonstrated that HDL$\mathrm{C}$ increases the activity of endothelial NO synthase (eNOS), antagonizes the actions of oxidized LDL-C on the endothelium, restores the balance between $\mathrm{NO}$ and superoxide $\left(\mathrm{O}_{2}^{-}\right)$, promotes endothelial cell proliferation and migration, and inhibits endothelial cell apoptosis [47-52].

Previous studies in various groups of patients regarding the short-term effects of statins on endothelial dysfunction have reported that statins could improve endothelial function significantly as early as three hours after treatment and even with a single dose [23-27]. The present study identified a significant improvement in brachial artery FMD\% among MS patients after treatment with $40 \mathrm{mg}$ atorvastatin daily for one week. Statin treatment improved brachial artery FMD\% significantly in patients without hypertension compared with patients with hypertension $(p=0.04)$. After statin treatment, a significant improvement in brachial artery FMD was detected in diabetics and non-diabetics, with a more pronounced effect in non-diabetics $(p=0.021)$. Among patients with both hypertension and DM, statin treatment significantly improved FMD\% $(p=0.0015)$. In these patients, no significant correlation was detected between FMD\%, SBP, and FBS before statin treatment, but a significant negative correlation was identified between SBP, FBS, and FMD\% after statin treatment. As SBP and FBS values increased, the improvement with statin in terms of FMD\% was lessened.

Various mechanisms other than lipid lowering have been proposed to explain the anti-atherosclerotic effects of statins, including antioxidant activity and enhanced
NO activity [53,54]. Statins reportedly increase eNOS activity in vitro $[55,56]$. Because NO is associated with many anti-atherosclerotic effects, including the inhibition of monocyte migration and smooth muscle cell proliferation, an increase in the activity of eNOS in response to statins may partially explain their anti-atherosclerotic effects.

\section{Conclusion}

Newly detected MS patients with hypertension and DM were treated with anti-hypertensives including angiotensin-converting enzyme inhibitors, angiotensin receptor blockers, and antidiabetic drugs like glitazones. The effects of these drugs on endothelial function have not been established. MS is associated with endothelial dysfunction and decreased FMD of the brachial artery compared with controls. Statin treatment for one week significantly improved brachial artery endothelial function in MS patients.

\section{Study Limitations}

This study included several limitations. Our sample size was small, so our findings may not be generalizable to the broader MS community. We did not measure endothelium-independent (nitrate-induced) dilation. The use of nitroglycerine might have added further information regarding endothelial function. MS variables including HDL-C, triglycerides, and other parameters were not measured after statin treatment.

\section{REFERENCES}

[1] "Executive Summary of the Third Report of the National Cholesterol Education Program (NCEP) Expert Panel on Detection, Evaluation, and Treatment of High Blood Cholesterol in Adults (Adult Treatment Panel III)," JAMA, Vol. 285, No. 19, 2001, pp. 2486-2497. http://dx.doi.org/10.1001/jama.285.19.2486

[2] S. M. Grundy, H. B. Brewer Jr., J. I. Cleeman, S. C. Smith Jr. and C. Lenfant, "Definition of Metabolic Syndrome: Report of the National Heart, Lung, and Blood Institute/American Heart Association Conference on Scientific Issues Related to Definition," Circulation, Vol. 109, No. 3, 2004, pp. 433-438. 
http://dx.doi.org/10.1161/01.CIR.0000111245.75752.C6

[3] B. Isomaa, P. Almgren, T. Tuomi, B. Forsen, K. Lahti, M. Nissen, M. R. Taskinen and L. Groop, "Cardiovascular Morbidity and Mortality Associated with the Metabolic Syndrome,” Diabetes Care, Vol. 24, No. 4, 2001, pp. 683689. http://dx.doi.org/10.2337/diacare.24.4.683

[4] D. S. Celermajer, K. E. Sorensen, V. M. Gooch, D. J. Spiegelhalter, O. I. Miller, I. D. Sullivan, J. K. Lloyd and J. E. Deanfield, "Non-Invasive Detection of Endothelial Dysfunction in Children and Adults at Risk of Atherosclerosis," Lancet, Vol. 340, No. 8828, 1992, pp. 1111-1115. http://dx.doi.org/10.1016/0140-6736(92)93147-F

[5] K. G. Reddy, R. N. Nair, H. M. Sheehan and J. M. Hodgson, "Evidence That Selective Endothelial Dysfunction May Occur in the Absence of Angiographic or Ultrasound Atherosclerosis in Patients with Risk Factors for Atherosclerosis," Journal of the American College of Cardiology, Vol. 23, No. 4, 1994, pp. 833-843. http://dx.doi.org/10.1016/0735-1097(94)90627-0

[6] M. E. Widlansky, N. Gokce, J. F. Keaney Jr. and J. A. Vita, "The Clinical Implications of Endothelial Dysfunction," Journal of the American College of Cardiology, Vol. 42, No. 7, 2003, pp. 1149-1160. http://dx.doi.org/10.1016/S0735-1097(03)00994-X

[7] D. S. Celermajer, "Endothelial Dysfunction: Does It Matter? Is It Reversible?” Journal of the American College of Cardiology, Vol. 30, No. 2, 1997, pp. 325-333. http://dx.doi.org/10.1016/S0735-1097(97)00189-7

[8] E. J. Benjamin, M. G. Larson, M. J. Keyes, G. F. Mitchell, R. S. Vasan, J. F. Keaney Jr., B. T. Lehman, S. Fan, E. Osypiuk and J. A. Vita, "Clinical Correlates and Heritability of Flow-Mediated Dilation in the Community: The Framingham Heart Study," Circulation, Vol. 109, No. 5, 2004, pp. 613-619.

http://dx.doi.org/10.1161/01.CIR.0000112565.60887.1E

[9] C. J. Rodriguez, Y. Miyake, C. Grahame-Clarke, M. R. Di Tullio, R. R. Sciacca, B. Boden-Albala, R. L. Sacco and S. Homma, "Relation of Plasma Glucose and Endothelial Function in a Population-Based Multiethnic Sample of Subjects without Diabetes Mellitus," American Journal of Cardiology, Vol. 96, No. 9, 2005, pp. 12731277. http://dx.doi.org/10.1016/j.amjcard.2005.06.070

[10] J. T. Kuvin, A. R. Patel, M. Sidhu, W. M. Rand, K. A. Sliney, N. G. Pandian and R. H. Karas, "Relation between High-Density Lipoprotein Cholesterol and Peripheral Vasomotor Function," American Journal of Cardiology, Vol. 92, No. 3, 2003, pp. 275-279. http://dx.doi.org/10.1016/S0002-9149(03)00623-4

[11] R. D. Brook, R. L. Bard, M. Rubenfire, P. M. Ridker and S. Rajagopalan, "Usefulness of Visceral Obesity (Waist/ Hip Ratio) in Predicting Vascular Endothelial Function in Healthy Overweight Adults," American Journal of Cardiology, Vol. 88, No. 11, 2001, pp. 1264-1269. http://dx.doi.org/10.1016/S0002-9149(01)02088-4

[12] J. A. Suwaidi, S. Hamasaki, S. T. Higano, R. A. Nishimura, D. R. Holmes Jr. and A. Lerman, "Long-Term Follow-Up of Patients with Mild Coronary Artery Disease and Endothelial Dysfunction," Circulation, Vol. 101, No. 9, 2000, pp. 948-954.
http://dx.doi.org/10.1161/01.CIR.101.9.948

[13] V. Schachinger, M. B. Britten and A. M. Zeiher, "Prognostic Impact of Coronary Vasodilator Dysfunction on Adverse Long-Term Outcome of Coronary Heart Disease,” Circulation, Vol. 101, No. 16, 2000, pp. 1899-1906. http://dx.doi.org/10.1161/01.CIR.101.16.1899

[14] J. P. Halcox, W. H. Schenke, G. Zalos, R. Mincemoyer, A. Prasad, M. A. Waclawiw, K. R. Nour and A. A. Quyyumi, "Prognostic Value of Coronary Vascular Endothelial Dysfunction," Circulation, Vol. 106, No. 6, 2002, pp. 653-658.

http://dx.doi.org/10.1161/01.CIR.0000025404.78001.D8

[15] F. Perticone, R. Ceravolo, A. Pujia, G. Ventura, S. Iacopino, A. Scozzafava, A. Ferraro, M. Chello, P. Mastroroberto, P. Verdecchia and G. Schillaci, "Prognostic Significance of Endothelial Dysfunction in Hypertensive Patients,” Circulation, Vol. 104, No. 2, 2001, pp. 191-196. http://dx.doi.org/10.1161/01.CIR.104.2.191

[16] M. C. Corretti, T. J. Anderson, E. J. Benjamin, D. Celermajer, F. Charbonneau, M. A. Creager, J. Deanfield, H. Drexler, M. Gerhard-Herman, D. Herrington, P. Vallance, J. Vita and R. Vogel, "Guidelines for the Ultrasound Assessment of Endothelial-Dependent Flow-Mediated Vasodilation of the Brachial Artery: A Report of the International Brachial Artery Reactivity Task Force,” Journal of the American College of Cardiology, Vol. 39, No. 2, 2002, pp. 257-265.

http://dx.doi.org/10.1016/S0735-1097(01)01746-6

[17] N. Gokce, J. F. Keaney Jr., L. M. Hunter, M. T. Watkins, Z. S. Nedeljkovic, J. O. Menzoian and J. A. Vita, "Predictive Value of Noninvasively Determined Endothelial Dysfunction for Long-Term Cardiovascular Events in Patients with Peripheral Vascular Disease," Journal of the American College of Cardiology, Vol. 41, No. 10, 2003, pp. 1769-1775. http://dx.doi.org/10.1016/S0735-1097(03)00333-4

[18] J. A. Vita and J. F. Keaney Jr., "Endothelial Function: A Barometer for Cardiovascular Risk?” Circulation, Vol. 106, No. 6, 2002, pp. 640-642. http://dx.doi.org/10.1161/01.CIR.0000028581.07992.56

[19] "Randomised Trial of Cholesterol Lowering in 4444 Patients with Coronary Heart Disease: The Scandinavian Simvastatin Survival Study (4S),” Lancet, Vol. 344, No. 8934, 1994, pp. 1383-1389.

[20] "Influence of Pravastatin and Plasma Lipids on Clinical Events in the West of Scotland Coronary Prevention Study (WOSCOPS),” Circulation, Vol. 97, No. 15, 1998, pp. 1440-1445. http://dx.doi.org/10.1161/01.CIR.97.15.1440

[21] F. M. Sacks, M. A. Pfeffer, L. A. Moye, J. L. Rouleau, J. D. Rutherford, T. G. Cole, L. Brown, J. W. Warnica, J. M. Arnold, C. C. Wun, B. R. Davis and E. Braunwald, "The Effect of Pravastatin on Coronary Events after Myocardial Infarction in Patients with Average Cholesterol Levels. Cholesterol and Recurrent Events Trial Investigators," The New England Journal of Medicine, Vol. 335, No. 14, 1996, pp. 1001-1009. http://dx.doi.org/10.1056/NEJM199610033351401

[22] G. O’Driscoll, D. Green and R. R. Taylor, “Simvastatin, 
an HMG-Coenzyme A Reductase Inhibitor, Improves Endothelial Function within 1 Month," Circulation, Vol. 95, No. 5, 1997, pp. 1126-1131.

http://dx.doi.org/10.1161/01.CIR.95.5.1126

[23] K. Iida, S. Goland, T. Akima, H. Luo, Y. Birnbaum and R. J. Siegel, "Effect of a Single 20-mg Tablet of Atorvastatin on Brachial Artery Blood Flow in Normolipidemic Male Smokers versus Nonsmokers," American Journal of Cardiology, Vol. 100, No. 5, 2007, pp. 881-884.

http://dx.doi.org/10.1016/j.amjcard.2007.04.021

[24] E. Taneva, K. Borucki, L. Wiens, R. Makarova, C. SchmidtLucke, C. Luley and S. Westphal, "Early Effects on Endothelial Function of Atorvastatin $40 \mathrm{mg}$ Twice Daily and Its Withdrawal," American Journal of Cardiology, Vol. 97, No. 7, 2006, pp. 1002-1006. http://dx.doi.org/10.1016/j.amjcard.2005.10.032

[25] T. Tsunekawa, T. Hayashi, H. Kano, D. Sumi, H. MatsuiHirai, N. K. Thakur, K. Egashira and A. Iguchi, "Cerivastatin, a Hydroxymethylglutaryl Coenzyme a Reductase Inhibitor, Improves Endothelial Function in Elderly Diabetic Patients within 3 Days," Circulation, Vol. 104, No. 4, 2001, pp. 376-379. http://dx.doi.org/10.1161/hc2901.094094

[26] E. Karatzis, J. Lekakis, C. Papamichael, I. Andreadou, A. Cimponeriu, K. Aznaouridis, T. G. Papaioannou, A. Protogerou and M. Mavrikakis, "Rapid Effect of Pravastatin on Endothelial Function and Lipid Peroxidation in Unstable Angina," International Journal of Cardiology, Vol. 101, No. 1, 2005, pp. 65-70. http://dx.doi.org/10.1016/j.ijcard.2004.03.060

[27] H. Omori, H. Nagashima, Y. Tsurumi, A. Takagi, N. Ishizuka, N. Hagiwara, M. Kawana and H. Kasanuki, "Direct in Vivo Evidence of a Vascular Statin: A Single Dose of Cerivastatin Rapidly Increases Vascular Endothelial Responsiveness in Healthy Normocholesterolaemic Subjects," British Journal of Clinical Pharmacology, Vol. 54, No. 4, 2002, pp. 395-399.

http://dx.doi.org/10.1046/j.1365-2125.2002.01677.x

[28] A. V. Chobanian, G. L. Bakris, H. R. Black, W. C. Cushman, L. A. Green, J. L. Izzo Jr., D. W. Jones, B. J. Materson, S. Oparil, J. T. Wright Jr. and E. J. Roccella, “The Seventh Report of the Joint National Committee on Prevention, Detection, Evaluation, and Treatment of High Blood Pressure: The JNC 7 Report,” JAMA, Vol. 289, No. 19, 2003, pp. 2560-2572. http://dx.doi.org/10.1001/jama.289.19.2560

[29] W. T. Friedewald, R. I. Levy and D. S. Fredrickson, "Estimation of the Concentration of Low-Density Lipoprotein Cholesterol in Plasma, without Use of the Preparative Ultracentrifuge," Clinical Chemistry, Vol. 18, No. 6, 1972, pp. 499-502.

[30] American Diabetes Association, "Diagnosis and Classification of Diabetes Mellitus,” Diabetes Care, Vol. 30, No. 1, pp. S42-S47. http://dx.doi.org/10.2337/dc07-S042

[31] N. Sattar, A. Gaw, O. Scherbakova, I. Ford, D. S. O’Reilly, S. M. Haffner, C. Isles, P. W. Macfarlane, C. J. Packard, S. M. Cobbe and J. Shepherd, "Metabolic Syndrome with and without C-Reactive Protein as a Predictor of Coronary Heart Disease and Diabetes in the West of Scotland Coronary Prevention Study,” Circulation, Vol.
108, No. 4, 2003, pp. 414-419.

http://dx.doi.org/10.1161/01.CIR.0000080897.52664.94

[32] H. M. Lakka, D. E. Laaksonen, T. A. Lakka, L. K. Niskanen, E. Kumpusalo, J. Tuomilehto and J. T. Salonen, "The Metabolic Syndrome and Total and Cardiovascular Disease Mortality in Middle-Aged Men,” JAMA, Vol. 288, No. 21, 2002, pp. 2709-2716. http://dx.doi.org/10.1001/jama.288.21.2709

[33] P. Libby, "Current Concepts of the Pathogenesis of the Acute Coronary Syndromes,” Circulation, Vol. 104, No. 3, 2001, pp. 365-372. http://dx.doi.org/10.1161/01.CIR.104.3.365

[34] K. Egashira, Y. Hirooka, H. Kai, M. Sugimachi, S. Suzuki, T. Inou and A. Takeshita, "Reduction in Serum Cholesterol with Pravastatin Improves Endothelium-Dependent Coronary Vasomotion in Patients with Hypercholesterolemia," Circulation, Vol. 89, No. 6, 1994, pp. 25192524. http://dx.doi.org/10.1161/01.CIR.89.6.2519

[35] N. Gokce, J. F. Keaney Jr., L. M. Hunter, M. T. Watkins, J. O. Menzoian and J. A. Vita, "Risk Stratification for Postoperative Cardiovascular Events via Noninvasive Assessment of Endothelial Function: A Prospective Study,” Circulation, Vol. 105, No. 13, 2002, pp. 1567-1572. http://dx.doi.org/10.1161/01.CIR.0000012543.55874.47

[36] G. Brevetti, A. Silvestro, V. Schiano and M. Chiariello, "Endothelial Dysfunction and Cardiovascular Risk Prediction in Peripheral Arterial Disease: Additive Value of Flow-Mediated Dilation to Ankle-Brachial Pressure Index," Circulation, Vol. 108, No. 17, 2003, pp. 2093-2098. http://dx.doi.org/10.1161/01.CIR.0000095273.92468.D9

[37] D. Shimbo, C. Grahame-Clarke, Y. Miyake, C. Rodriguez, R. Sciacca, M. Di Tullio, B. Boden-Albala, R. Sacco and S. Homma, "The Association between Endothelial Dysfunction and Cardiovascular Outcomes in a PopulationBased Multi-Ethnic Cohort,” Atherosclerosis, Vol. 192, No. 1, 2007, pp. 197-203. http://dx.doi.org/10.1016/j.atherosclerosis.2006.05.005

[38] M. Frick, A. Suessenbacher, H. F. Alber, W. Dichtl, H. Ulmer, O. Pachinger and F. Weidinger, "Prognostic Value of Brachial Artery Endothelial Function and Wall Thickness," Journal of the American College of Cardiology, Vol. 46, No. 6, 2005, pp. 1006-1010. http://dx.doi.org/10.1016/j.jacc.2005.05.070

[39] S. Y. Chan, G. B. Mancini, L. Kuramoto, M. Schulzer, J. Frohlich and A. Ignaszewski, "The Prognostic Importance of Endothelial Dysfunction and Carotid Atheroma Burden in Patients with Coronary Artery Disease," Journal of the American College of Cardiology, Vol. 42, No. 6, 2003, pp. 1037-1043.

http://dx.doi.org/10.1016/S0735-1097(03)00927-6

[40] T. D. Wang, W. J. Chen, J. W. Lin, M. F. Chen and Y. T. Lee, "Effects of Rosiglitazone on Endothelial Function, C-Reactive Protein, and Components of the Metabolic Syndrome in Nondiabetic Patients with the Metabolic Syndrome," American Journal of Cardiology, Vol. 93, No. 3, 2004, pp. 362-365.

http://dx.doi.org/10.1016/j.amjcard.2003.10.022

[41] R. D. Brook, R. L. Bard, M. Rubenfire, P. M. Ridker and S. Rajagopalan, "Usefulness of Visceral Obesity (Waist/ 
Hip Ratio) in Predicting Vascular Endothelial Function in Healthy Overweight Adults," American Journal of Cardiology, Vol. 88, No. 11, 2001, pp. 1264-1269. http://dx.doi.org/10.1016/S0002-9149(01)02088-4

[42] L. Lind, "Endothelium-Dependent Vasodilation, Insulin Resistance and the Metabolic Syndrome in an Elderly Cohort: the Prospective Investigation of the Vasculature in Uppsala Seniors (PIVUS) Study,” Atherosclerosis, Vol. 196, No. 2, 2008, pp. 795-802. http://dx.doi.org/10.1016/j.atherosclerosis.2007.01.014

[43] A. Lteif, K. Han and K. J. Mather, "Obesity, Insulin Resistance, and the Metabolic Syndrome: Determinants of Endothelial Dysfunction in Whites and Blacks," Circulation, Vol. 112, No. 1, 2005, pp. 32-38. http://dx.doi.org/10.1161/CIRCULATIONAHA.104.5201 $\underline{30}$

[44] G. Dell’Omo, G. Penno, L. Pucci, M. Mariani, S. Del Prato and R. Pedrinelli, “Abnormal Capillary Permeability and Endothelial Dysfunction in Hypertension with Comorbid Metabolic Syndrome," Atherosclerosis, Vol. 172, No. 2, 2004, pp. 383-389. http://dx.doi.org/10.1016/j.atherosclerosis.2003.11.013

[45] N. M. Hamburg, M. G. Larson, J. A. Vita, R. S. Vasan, M. J. Keyes, M. E. Widlansky, C. S. Fox, G. F. Mitchell, D. Levy, J. B. Meigs and E. J. Benjamin, "Metabolic Syndrome, Insulin Resistance, and Brachial Artery Vasodilator Function in Framingham Offspring Participants without Clinical Evidence of Cardiovascular Disease," American Journal of Cardiology, Vol. 101, No. 1, 2008, pp. 82-88. http://dx.doi.org/10.1016/j.amjcard.2007.07.053

[46] N. Melikian, P. Chowienczyk, P. A. MacCarthy, I. L. Williams, S. B. Wheatcroft, R. Sherwood, C. Gale, A. M. Shah and M. T. Kearney, "Determinants of Endothelial Function in Asymptomatic Subjects with and without the Metabolic Syndrome,” Atherosclerosis, Vol. 197, No. 1, 2008, pp. 375-382. http://dx.doi.org/10.1016/j.atherosclerosis.2007.06.009

[47] C. Mineo, H. Deguchi, J. H. Griffin and P. W. Shaul, "Endothelial and Antithrombotic Actions of HDL," Circulation Research, Vol. 98, No. 11, 2006, pp. 1352-1364. http://dx.doi.org/10.1161/01.RES.0000225982.01988.93

[48] I. S. Yuhanna, Y. Zhu, B. E. Cox, L. D. Hahner, S. Osborne-Lawrence, P. Lu, Y. L. Marcel, R. G. Anderson, M. E. Mendelsohn, H. H. Hobbs and P. W. Shaul, "HighDensity Lipoprotein Binding to Scavenger Receptor-BI Activates Endothelial Nitric Oxide Synthase," Nature Medicine, Vol. 7, No. 7, 2001, pp. 853-857. http://dx.doi.org/10.1038/89986

[49] Z. Ou, J. Ou, A. W. Ackerman, K. T. Oldham and K. A. Pritchard Jr., "L-4F, an Apolipoprotein A-1 Mimetic, Restores Nitric Oxide and Superoxide Anion Balance in
Low-Density Lipoprotein-Treated Endothelial Cells," Circulation, Vol. 107, No. 11, 2003, pp. 1520-1524. http://dx.doi.org/10.1161/01.CIR.0000061949.17174.B6

[50] J. Ou, J. Wang, H. Xu, Z. Ou, M. G. Sorci-Thomas, D. W. Jones, P. Signorino, J. C. Densmore, S. Kaul, K. T. Oldham and K. A. Pritchard Jr., "Effects of D-4F on Vasodilation and Vessel Wall Thickness in Hypercholesterolemic LDL Receptor-Null and LDL Receptor/Apolipoprotein A-I Double-Knockout Mice on Western Diet," Circulation Research, Vol. 97, No. 11, 2005, pp. 11901197.

http://dx.doi.org/10.1161/01.RES.0000190634.60042.cb

[51] T. Kimura, K. Sato, E. Malchinkhuu, H. Tomura, K. Tamama, A. Kuwabara, M. Murakami and F. Okajima, "HighDensity Lipoprotein Stimulates Endothelial Cell Migration and Survival through Sphingosine 1-Phosphate and Its Receptors,” Arteriosclerosis, Thrombosis, and Vascular Biology, Vol. 23, No. 7, 2003, pp. 1283-1288. http://dx.doi.org/10.1161/01.ATV.0000079011.67194.5A

[52] J. R. Nofer, B. Levkau, I. Wolinska, R. Junker, M. Fobker, A. von Eckardstein, U. Seedorf and G. Assmann, "Suppression of Endothelial Cell Apoptosis by High Density Lipoproteins (HDL) and HDL-Associated Lysosphingolipids,” The Journal of Biological Chemistry, Vol. 276, No. 37, 2001, pp. 34480-34485. http://dx.doi.org/10.1074/jbc.M103782200

[53] T. J. Anderson, I. T. Meredith, A. C. Yeung, B. Frei, A. P. Selwyn and P. Ganz, "The Effect of Cholesterol-Lowering and Antioxidant Therapy on Endothelium-Dependent Coronary Vasomotion," The New England Journal of Medicine, Vol. 332, No. 8, 1995, pp. 488-493. http://dx.doi.org/10.1056/NEJM199502233320802

[54] C. B. Treasure, J. L. Klein, W. S. Weintraub, J. D. Talley, M. E. Stillabower, A. S. Kosinski, J. Zhang, S. J. Boccuzzi, J. C. Cedarholm and R. W. Alexander, "Beneficial Effects of Cholesterol-Lowering Therapy on the Coronary Endothelium in Patients with Coronary Artery Disease," The New England Journal of Medicine, Vol. 332, No. 8, 1995, pp. 481-487. http://dx.doi.org/10.1056/NEJM199502233320801

[55] J. A. Beckman and M. A. Creager, "The Nonlipid Effects of Statins on Endothelial Function," Trends in Cardiovascular Medicine, Vol. 16, No. 5, 2006, pp. 156-162. http://dx.doi.org/10.1016/j.tcm.2006.03.003

[56] J. A. Beckman, J. K. Liao, S. Hurley, L. A. Garrett, D. Chui, D. Mitra and M. A. Creager, “Atorvastatin Restores Endothelial Function in Normocholesterolemic Smokers Independent of Changes in Low-Density Lipoprotein," Circulation Research, Vol. 95, No. 2, 2004, pp. 217-223. http://dx.doi.org/10.1161/01.RES.0000134628.96682.9b 